\title{
Aggressive Merkel Cell Carcinoma After Janus Kinase Inhibitor Ruxolitinib for Polycythemia Vera
}

\author{
MARCO RASTRELLI ${ }^{*}$, BEATRICE FERRAZZI ${ }^{2 *}$, SAVERIA TROPEA $^{1}$, \\ ALESSANDRA COSTA $^{1}$, SILVIA FINOTTO ${ }^{3}$, DARIO MARINO ${ }^{3}$, LUCA CAMPANA $^{1}$, \\ PAOLO DEL FIORE ${ }^{1}$, CARLO RICCARDO ROSSI ${ }^{1}$ and MAURO ALAIBAC ${ }^{2}$ \\ ${ }^{1}$ Surgical Oncology Unit, Veneto Institute of Oncology IOV - IRCCS, Padua, Italy; \\ ${ }^{2}$ Dermatology Unit, Department of Medicine (DIMED), University of Padua, Padua, Italy; \\ ${ }^{3}$ Medical Oncology 1, Department of Oncology, Veneto Institute of Oncology IOV-IRCCS, Padua, Italy
}

\begin{abstract}
Merkel cell carcinoma (MCC) is a rare neuroendocrine carcinoma of the skin. It is highly aggressive and represents the second most common cause of skin cancerrelated death. Ruxolitinib is an orally administered selective inhibitor of Janus associated kinases 1 and 2, which is used in the management of patients with symptomatic myelofibrosis and polycythemia vera who are non-responders or intolerant to hydroxyurea. Herein, we report the case of a 47-year-old woman with a 14-year history of chronic myeloproliferative syndrome initially treated with hydroxyurea for 4 years. She was then enrolled in the Response trial and treated for 7 years with ruxolitinib subsequently developing an MCC. This report shows the possibility of development of MCC in patients treated with ruxolitinib. Periodic skin examination is indicated in patients who undergo ruxolitinib therapy, especially if they have a history of skin cancer; dermatologists and oncohematologists should be aware of this possibility in order to introduce appropriate preventive strategies.
\end{abstract}

Merkel cell carcinoma (MCC) is a rare neuroendocrine carcinoma of the skin. It is highly aggressive and is the second most common cause of skin cancer-related death (1). MCC is usually asymptomatic, but has rapid growth. It frequently occurs on the head, neck and arms in skin exposed to sunlight $(1,2)$.

This article is freely accessible online.

*These Authors contributed equally to this work.

Correspondence to: Mauro Alaibac, Dermatology Unit, Department of Medicine (DIMED), University of Padova, Via V. Gallucci, 4, 35121 Padova, Italy. Tel: +39 3293716018, e-mail: mauro.alaibac@unipd.it

Key Words: Merkel cell carcinoma, polycythemia vera, myelofibrosis, ruxolitinib, response trial, immunomodulatory drugs.
The immune system has an essential role in preventing the development of MCC and in counteracting its progression and $10 \%$ of patients affected by MCC are immune suppressed (3).

Ruxolitinib is an orally administered selective inhibitor of Janus-associated kinases (JAK) 1 and 2 used in the management of patients with symptomatic myelofibrosis and polycythemia vera $(\mathrm{PV})$ who are non-responders or intolerant to hydroxyurea. Clinical trials with ruxolitinib have demonstrated significant benefits in terms of reductions of splenomegaly and increased control of disease-related symptoms with improving quality of life in patient with myeloproliferative disease compared with best available therapy (BAT) (4-7). Most common adverse events of ruxolitinib therapy are correlated with hematological toxicity, in particular anemia and thrombocytopenia; it is also associated with a potentially increased risk of opportunist infections. In general, ruxolitib is well tolerated and discontinuation due to adverse events is rare.

In the 5-year analysis of the COMFORT-II trial, a phase III study comparing ruxolitinib to BAT in patients with myelofibrosis, $17.1 \%$ of patients in the ruxolitinib-treated arm had newly diagnosed non-melanoma skin cancer, compared to $2.7 \%$ in BAT-treated arm. In the RESPONSE trial, a phase III study comparing ruxolitinib to BAT in patients with $\mathrm{PV}$, the rates of non-melanoma skin cancer per 100 patient-years of exposure were 4.4 and 2.7 , respectively.

In this article, we describe a case of MCC in a patient with myeloproliferative syndrome treated with ruxolitinib.

\section{Case Report}

A 47-year-old woman with a 14-year history of chronic myeloproliferative syndrome treated firstly with hydroxyurea for 4 years and then for 7 years with ruxolitinib presented with a rapidly expanding, solitary, red-to-violet nodule on her right elbow which had appeared 5 months previously. The patient 
had familial history of hypertension and cardiovascular diseases but not with cancer. She had been under treatment with atenolol since 2002. This patient had metabolic comorbidities such as hyperlipidemia and hypertriglyceridemia, and her body mass index (BMI) had increased from 29 to 37 during the previous 10 years. In 2004, the patient was diagnosed with JAK2 V617F+ PV and started phlebotomy and once-daily aspirin. Three years later, an increase in white blood cell count and platelet level was observed, consequently therapy was switched to oral hydroxyurea. In 2011, due to the worsening of splenomegaly and poor control of blood cell count, the patient was enrolled in the RESPONSE trial, a randomized, open label, multicenter phase IIIb study evaluating the efficacy and safety of ruxolitinib compared with BAT in patients with PV resistant or intolerant to hydroxyurea.

Firstly, our patient received $10 \mathrm{mg}$ twice daily and then 20 mg twice daily for 7 years (from December 2011 to February 2018). Control of her hematocrit level was good and there was a reduction of spleen volume $>35 \%$. In March 2018, she presented with a rapidly expanding, solitary, red-to-violet nodule on her right elbow which had appeared 5 months previously. The tumor stained positively with CAM5.2 for cytokeratin 7 and 8, and for cytokeratin 20 and synaptophysin, and proved to be MCC with lymph node involvement. A trucut biopsy and then core-needle biopsy were performed in the diagnostic process. The right axillary lymph nodes appeared clinically, radiologically and histologically involved. In July 2018, the patient underwent wide excision of the lesion and complete lymph node dissection. The pathological examination revealed clear margins, nodal involvement $(6+/ 38)$ and lymphovascular invasion. After multidisciplinary discussion, in August 2018, the patient underwent local radiation therapy (54 Gy dose radiation in 27 sessions). At the check up at 1 year after surgery, there was no evidence of disease.

\section{Discussion}

Immune suppression is one of the main risk factors for the development of MCC, as suggested by its high incidence in patients with hematological malignancies, HIV infection, organ transplantation and in those treated with immunesuppressive drugs (3). Moreover, when a patient is affected by MCC when receiving immunomodulatory drugs for the treatment of other comorbidities, this is associated with impaired disease-specific and disease-free survival (8). Failure of immune surveillance of cancer due to iatrogenic immune suppression caused by immunomodulatory drugs may explain the impaired survival of such patients.

The administration of oral ruxolitinib to patients markedly reduced splenomegaly and circulating levels of proinflammatory cytokines and eliminated neoplastic cells with mutated $J A K 2$ (9). JAK $1 / 2$ inhibitors reduce the signaling of pathogenic cytokines such as interleukin- 6 and -23 , and as a result they can inhibit the production of an array of additional proinflammatory cytokines, chemokines, and adhesion molecules produced by other cell types, leading to interruption of the cytokine cascade $(10,11)$.

Our patient developed MCC during long treatment with ruxolitinib and had been treated in the past with hydroxyurea, an anti-metabolite also associated with many cutaneous adverse effects ranging in severity from ichthyosis to aggressive non-melanoma skin cancer $(12,13)$. Therefore, iatrogenic immune suppression due to the pharmacological treatment received by our patient might have been the cause of MCC development (14-16).

Periodic skin examination should be offered to patients who receive ruxolitinib therapy, especially if they have a history of skin cancer; dermatologists and oncohematologists should be aware of this possibility in order to undertake appropriate preventive measures.

\section{Funding}

No external funding was provided.

\section{Availability of Data and Materials}

The dataset used and/or analyzed during the current study is available from the corresponding Author on reasonable request.

\section{Ethics Approval and Consent to Participate}

No. 4/2018 on 23 July 2018.

\section{Consent for Publication}

The patient gave her approval for publication.

\section{Conflicts of Interest}

The Authors declare no conflict of interest.

\section{Authors' Contributions}

Conceptualization: Mauro Alaibac, Marco Rastrelli; Collection of medical follow up data: Paolo Del Fiore, Beatrice Ferrazzi; Collection of surgical follow up: Saveria Tropea; Data Collection: Beatrice Ferrazzi, Paolo Del Fiore, Alessandra Costa; WritingOriginal Draft Preparation: Beatrice Ferrazzi, Silvia Finotto; All Authors read and approved the final article.

\section{References}

1 Schadendorf D, Lebbé C, Zur Hausen A, Avril MF, Hariharan S, Bharmal M and Becker JC: Merkel cell carcinoma: Epidemiology, prognosis, therapy and unmet medical needs. Eur J Cancer 71: 5369, 2017. PMID: 27984768. DOI: 10.1016/ j.ejca.2016.10.022

2 Müller-Richter UDA, Gesierich A, Kübler AC, Hartmann S and Brands RC: Merkel cell carcinoma of the head and neck: 
Recommendations for diagnostics and treatment. Ann Surg Oncol 24(11): 3430-3437, 2017. PMID: 28762116. DOI: 10.1245/s10434-017-5993-1

3 Paulson KG, Iyer JG, Blom A, Warton EM, Sokil M, Yelistratova L, Schuman L, Nagase K, Bhatia S, Asgari MM and Nghiem P: Systemic immune suppression predicts diminished Merkel cell carcinoma-specific survival independent of stage. J Invest Dermatol 133(3): 642-646, 2013. PMID: 23190897. DOI: 10.1038/jid.2012.388

4 Verstovsek S, Vannucchi AM, Griesshammer M, Masszi T, Durrant S, Passamonti F, Harrison CN, Pane F, Zachee P, Kirito K, Besses C, Hino M, Moiraghi B, Miller CB, Cazzola M, Rosti V, Blau I, Mesa R, Jones MM, Zhen H, Li J, Francillard N, Habr $\mathrm{D}$ and Kiladjian JJ: Ruxolitinib versus best available therapy in patients with polycythemia vera: 80 -week follow-up from the RESPONSE trial. Haematologica 101(7): 821-829, 2016. PMID: 27102499. DOI: 10.3324 /haematol.2016.143644

5 Assi R, Kantarjian HM, Garcia-Manero G, Cortes JE, Pemmaraju N, Wang X, Nogueras-Gonzalez G, Jabbour E, Bose P, Kadia T, Dinardo CD, Patel K, Bueso-Ramos C, Zhou L, Pierce S, Gergis R, Tuttle C, Borthakur G, Estrov Z, Luthra R, Hidalgo-Lopez J, Verstovsek S and Daver N: A phase II trial of ruxolitinib in combination with azacytidine in myelodysplastic syndrome/myeloproliferative neoplasms. Am J Hematol 93(2): 277-285, 2018. PMID: 29134664. DOI: 10.1002/ajh.24972

6 Verstovsek S, Mesa RA, Gotlib J, Gupta V, DiPersio JF, Catalano JV, Deininger MW, Miller CB, Silver RT, Talpaz M, Winton EF, Harvey JH Jr, Arcasoy MO, Hexner EO, Lyons RM, Paquette R, Raza A, Jones M, Kornacki D, Sun K, Kantarjian H and COMFORT-I investigators: Long-term treatment with ruxolitinib for patients with myelofibrosis: 5-year update from the randomized, double-blind, placebo-controlled, phase 3 COMFORT-I trial. J Hematol Oncol 10(1): 55, 2017. PMID: 28228106. DOI: 10.1186/s13045-017-0417-z

7 Padron E, Dezern A, Andrade-Campos M, Vaddi K, Scherle P, Zhang Q, Ma Y, Balasis ME, Tinsley S, Ramadan H, Zimmerman C, Steensma DP, Roboz GJ, Lancet JE, List AF, Sekeres MA and Komrokji RS: A multi-institution phase I trial of ruxolitinib in patients with chronic myelomonocytic leukemia (CMML). Clin Cancer Res 22(15): 3746-3754, 2016. PMID: 26858309. DOI: 10.1158/1078-0432.CCR-15-2781

8 Rastrelli M, Ferrazzi B, Cavallin F, Chiarion Sileni V, Pigozzo J, Fabozzi A, Tropea S, Vecchiato A, Costa A, Parisi A, Rossi CR, Del Fiore P and Alaibac M: Prognostic factors in Merkel cell carcinoma: A retrospective single-center study in 90 patients. Cancers (Basel) 10(10): pii: E350, 2018. PMID: 30249 978. DOI: $10.3390 /$ cancers 10100350
9 Kiladjian JJ, Guglielmelli P, Griesshammer M, Saydam G, Masszi T, Durrant S, Passamonti F, Jones M, Zhen H, Li J, Gadbaw B, Perez Ronco J, Khan M and Verstovsek S: Efficacy and safety of ruxolitinib after and versus interferon use in the RESPONSE studies. Ann Hematol 97(4): 617-627, 2018. PMID: 29396713. DOI: 10.1007/s00277-017-3225-1

10 Quintás-Cardama A, Vaddi K, Liu P, Manshouri T, Li J, Scherle PA, Caulder E, Wen X, Li Y, Waeltz P, Rupar M, Burn T, Lo Y, Kelley J, Covington M, Shepard S, Rodgers JD, Haley P, Kantarjian H, Fridman JS and Verstovsek S: Preclinical characterization of the selective JAK1/2 inhibitor INCB018424: therapeutic implications for the treatment of myeloproliferative neoplasms. Blood 115(15): 3109-3117, 2010. PMID: 20130243. DOI: $10.1182 /$ blood-2009-04-214957

11 Mascarenhas $\mathrm{J}$ and Hoffman R: Ruxolitinib: the first FDA approved therapy for the treatment of myelofibrosis. Clin Cancer Res 18(11): 3008-3014, 2012. doi: PMID: 22474318. DOI: 10.1158/1078-0432.CCR-11-3145

12 Neill B, Ryser T, Neill J, Aires D and Rajpara A: A patient case highlighting the myriad of cutaneous adverse effects of prolonged use of hydroxyurea. Dermatol Online J 23(11): pii: 13030/qt8h64503t, 2017. PMID: 29447639.

13 Verner E, Forsyth C and Grigg A: Cyclical thrombocytosis, acquired von Willebrand syndrome and aggressive nonmelanoma skin cancers are common in patients with Philadelphia-negative myeloproliferative neoplasms treated with hydroxyurea. Leuk Lymphoma 55(5): 1139-1143, 2014. PMID: 23879199. DOI: $10.3109 / 10428194.2013 .827788$

14 Blechman AB, Cabell CE, Weinberger CH, Duckworth A, Leitenberger JJ, Zwald FO and Russell MA: Aggressive skin cancers occurring in patients treated with the janus kinase inhibitor ruxolitinib. J Drugs Dermatol 16(5): 508-511, 2017. PMID: 28628689.

15 Curto-Garcia N and Harrison CN: An updated review of the JAK1/2 inhibitor (ruxolitinib) in the Philadelphia-negative myeloproliferative neoplasms. Future Oncol 14(2): 137-150, 2018. PMID: 29056075. DOI: 10.2217/fon-2017-0298

16 Fabiano A, Calzavara-Pinton P, Monari P, Moggio E, Pellacani G, Manganoni AM and Gualdi G: Eruptive squamous cell carcinomas with keratoacanthoma-like features in a patient treated with ruxolitinib. Br J Dermatol 173(4): 1098-1099, 2015. PMID: 25997466. DOI: 10.1111/bjd.13922

Received April 25, 2019

Revised June 20, 2019

Accepted June 28, 2019 